\title{
Measurement of geologic nitrogen using mass spectrometry, colorimetry, and a newly adapted fluorometry technique
}

\author{
Benjamin W. Johnson ${ }^{1}$, Natashia Drage ${ }^{1}$, Jody Spence ${ }^{1}$, Nova Hanson ${ }^{2}$, Rana El-Sabaawi ${ }^{2}$, and Colin Goldblatt ${ }^{1}$ \\ ${ }^{1}$ School of Earth and Ocean Sciences, University of Victoria, Victoria, BC, Canada \\ ${ }^{2}$ Department of Biology, University of Victoria, Victoria, BC, Canada \\ Correspondence to: Benjamin W. Johnson (bwjohnso@uvic.ca)
}

Received: 11 November 2016 - Discussion started: 23 November 2016

Revised: 11 February 2017 - Accepted: 27 February 2017 - Published: 10 March 2017

\begin{abstract}
Long viewed as a mostly noble, atmospheric species, recent work demonstrates that nitrogen in fact cycles throughout the Earth system, including the atmosphere, biosphere, oceans, and solid Earth. Despite this new-found behaviour, more thorough investigation of $\mathrm{N}$ in geologic materials is limited due to its low concentration (one to tens of parts per million) and difficulty in analysis. In addition, $\mathrm{N}$ can exist in multiple species $\left(\mathrm{NO}_{3}^{-}, \mathrm{NH}_{4}^{+}, \mathrm{N}_{2}\right.$, organic $\left.\mathrm{N}\right)$, and determining which species is actually quantified can be difficult. In rocks and minerals, $\mathrm{NH}_{4}^{+}$is the most stable form of $\mathrm{N}$ over geologic timescales. As such, techniques designed to measure $\mathrm{NH}_{4}^{+}$can be particularly useful.

We measured a number of geochemical rock standards using three different techniques: elemental analyzer (EA) mass spectrometry, colorimetry, and fluorometry. The fluorometry approach is a novel adaptation of a technique commonly used in biologic science, applied herein to geologic $\mathrm{NH}_{4}^{+}$. Briefly, $\mathrm{NH}_{4}^{+}$can be quantified by HF dissolution, neutralization, addition of a fluorescing reagent, and analysis on a standard fluorometer. We reproduce published values for several rock standards (BCR-2, BHVO-2, and G-2), especially if an additional distillation step is performed. While it is difficult to assess the quality of each method, due to lack of international geologic $\mathrm{N}$ standards, fluorometry appears better suited to analyzing mineral-bound $\mathrm{NH}_{4}^{+}$than EA mass spectrometry and is a simpler, quicker alternative to colorimetry.

To demonstrate a potential application of fluorometry, we calculated a continental crust $\mathrm{N}$ budget based on new measurements. We used glacial tills as a proxy for upper crust and analyzed several poorly constrained rock types (volcanics, mid-crustal xenoliths) to determine that the continental crust contains $\sim 2 \times 10^{18} \mathrm{~kg} \mathrm{~N}$. This estimate is consistent with
\end{abstract}

recent budget estimates and shows that fluorometry is appropriate for large-scale questions where high sample throughput is helpful.

Lastly, we report the first $\delta^{15} \mathrm{~N}$ values of six rock standards: BCR-2 $(1.05 \pm 0.4 \%$ ) , BHVO-2 $(-0.3 \pm 0.2 \%)$, G$2(1.23 \pm 1.32 \%$ ) , LKSD-4 (3.59 $\pm 0.1 \%$ ), Till-4 $(6.33 \pm$ $0.1 \% o)$, and SY-4 (2.13 $\pm 0.5 \% o)$. The need for international geologic $\mathrm{N}$ standards is crucial for further investigation of the Earth system $\mathrm{N}$ cycle, and we suggest that existing rock standards may be suited to this need.

\section{Introduction}

Since its classification as an atmophile element by Goldschmidt (1937), the fate and nature of $\mathrm{N}$ in rocks and minerals has received little attention. Many early budgets suggested most of Earth's $\mathrm{N}$ was in the atmosphere, with only minor amounts in the biosphere, crust, and mantle (e.g., Wlotzka, 1972). And while concentrations in rocks and minerals are low, typically one to tens of parts per million, the great mass of the bulk silicate Earth (BSE) compared to the atmosphere allows for a substantial amount of planetary $\mathrm{N}$ to be contained in the BSE. In fact, the BSE and core likely contain the majority of $\mathrm{N}$ in the Earth (Johnson and Goldblatt, 2015). In addition, enriched $\delta^{15} \mathrm{~N}$ values from mantlederived rocks and the correlation of $\mathrm{N}_{2}$ with ${ }^{40} \mathrm{Ar}$ indicate that $\mathrm{N}$ has cycled between the surface and the deeper planet over geologic time (Marty, 1995; Busigny et al., 2011; Barry and Hilton, 2016).

In spite of the new-found richness of the geologic $\mathrm{N}$ cycle, the relative paucity of sample analyses limits robust interpre- 
tation or modelling of $\mathrm{N}$ cycling over Earth's history. This paucity is due in large part to the difficulty of measuring low concentrations of $\mathrm{N}$ in rocks and minerals. Though a variety of analytical techniques are now able to measure $\mathrm{N}$ at parts per million level concentrations in rocks and minerals (e.g., Bräuer and Hahne, 2005; Barry et al., 2012; von der Handt and Dalou, 2016), several of these are either analytically expensive or only operational at a handful of labs around the world. The development of techniques that are more easily accessible and able to be performed with standard geochemical equipment would be a great benefit to the community.

We first describe, briefly, existing techniques used to measure $\mathrm{N}$ in geologic samples. Classic techniques typically involve either whole rock or mineral dissolution in HF and/or $\mathrm{H}_{2} \mathrm{SO}_{4}$ (e.g., Honma and Itihara, 1981; Haendel et al., 1986). These techniques often involve hot digestion at temperatures greater than $90^{\circ} \mathrm{C}$ and sometimes up to hundreds of degrees Celsius. After extraction, samples are typically distilled using a Kjeldahl method, then analyzed using colorimetry (Nessler's reagent; Haendel et al., 1986). Alternatively, samples could be oxidized under high temperatures $\left(800-1000^{\circ} \mathrm{C}\right.$ ) in sealed tubes with $\mathrm{CuO}$ and $\mathrm{CaO}$ (Bebout and Fogel, 1992). Extracted $\mathrm{N}$ could be inserted into a mass spectrometer for isotopic characterization. Extraction of $\mathrm{N}$ by thermal heating and release (e.g., Boyd, 1997; Yokochi et al., 2009) has also been applied to mineral separates and geologic samples. In addition, in situ analyses such as Fourier transform infrared microscopy have been used to determine $\mathrm{N}$ speciation (Boyd, 1997). Existing techniques can be wellsuited for measuring mineral-bound $\mathrm{NH}_{4}^{+}$. Many existing techniques, however, are either set up at only a few laboratories around the world (Bebout and Fogel, 1992; Barry et al., 2012), require high-temperature or aggressive chemical extractions (e.g., Haendel et al., 1986), or otherwise require lengthy mineral separations or dedicated extraction lines.

In this study, we adapt a fluorometry technique developed by Holmes et al. (1999) that is commonly used in biologic and aquatic chemistry studies and compare it with two other techniques: colorimetry (Hall, 1993) and elemental analyzer mass spectrometry (e.g., Stuieken, 2013). Through analysis of a number of rock standards, we demonstrate that, while this fluorometry technique has some associated uncertainty, it reproduces published values for standards BCR-2, BHVO2, and G-2, especially if a distillation step is undertaken. It also performs better than elemental analyzer combustion mass spectrometry or colorimetry methods for quantifying $\mathrm{N}$ in crystalline rocks. The fluorometry technique has the advantage over other techniques by being relatively fast, requiring few reagents, requiring more accessible analytical equipment, as well as specifically targeting $\mathrm{NH}_{4}^{+}$. There are three main benefits: the relative ease of the method which may increase the number of analyses of $\mathrm{N}$ in geologic samples, its use as a screening method that can be used to guide further isotopic investigation, and its specificity to $\mathrm{NH}_{4}^{+}$. We emphasize, however, that $\mathrm{N}$ isotopes cannot be measured with fluo-
Table 1. Rock standards from the United States Geological Survey (USGS) and Geological Survey of Canada (GSC) analyzed with published values, if available, and $\mathrm{N}$ analysis reference.

\begin{tabular}{llrr}
\hline Standard & Description & $\begin{array}{r}\text { N } \\
(\mathrm{ppm})\end{array}$ & Reference \\
& & $34 \pm 12$ & $1,2,3$ \\
BCR-1/2 & USGS Columbia river basalt & $22.6 \pm 3$ & 1,3 \\
BHVO-2 & USGS Hawaiian basalt & $34 \pm 4$ & 1,3 \\
G-2 & USGS Paleozoic granite & & \\
Till-4 & GSC Till from Scisson's Brook, & \\
LKSD-4 & New Brunswick & & \\
SY-4 & Dig Gull Lake sediment, Ontario gneiss, Ontario & & \\
\hline
\end{tabular}

${ }^{1}$ Govindaraju (1994). ${ }^{2}$ Norris and Schaeffer (1982). ${ }^{3}$ Murty et al. (1983).

rometry, and both fluorometry and colorimetry techniques require a period of rock digestion which other techniques may not require.

In addition, we also present a preliminary application of the method vis-á-vis a $\mathrm{N}$ budget for the continental crust based on glacial tills and crystalline crustal rocks from North America. Along with the atmosphere and mantle, the continental crust is one of the main $\mathrm{N}$ reservoirs on the planet (Goldblatt et al., 2009; Johnson and Goldblatt, 2015), thus determining its content is key in the evolution of the $\mathrm{N}$ cycle over time.

We also call for the development of international geologic $\mathrm{N}$ standards (after Ader et al., 2016). Method development for the measurement of geologic $\mathrm{N}$ suffers without such standards. We present the first $\delta^{15} \mathrm{~N}$ values of a number of rock standards (BCR-2, BHVO-2, SY-4, LKSD-4, Till-4, G-2) and suggest they may be suited for geologic $\mathrm{N}$ standards, given more thorough analysis.

\section{Methods}

\subsection{Rock standards and samples}

We analyzed a number of geochemical rock standards (Table 1). Several standards (LKSD-4, Till-4, SY-4) have no previous $\mathrm{N}$ concentration measurements, to our knowledge. Remaining standards have published $\mathrm{N}$ concentrations (BCR-2, BHVO-2, G-2), with values reported from neutron activation analysis (NAA). This technique works by irradiating samples with neutrons to transform ${ }^{14} \mathrm{~N}$ into ${ }^{14} \mathrm{C}$, where the resulting material can then be purified and assayed radiochemically as a proxy for N concentration (Shukla et al., 1978).

In addition to rock standards, we analyzed a number of other lithologies, including glacial tills, basalts, granites, and carbonates. These samples were chosen as a proof of concept for the adapted fluorometry technique, namely, investigating the $\mathrm{N}$ budget of the continental crust. All tills are from British Columbia, Canada, and have eroded a variety of Phanerozoic crustal lithologies. Basalts and welded tuffs are from the Bo- 
nanza Arc and Sicker Group on Vancouver Island, British Columbia. Granites come from a variety of locations in North America. Sample descriptions are given in the Supplement.

\subsection{Rock sample preparation}

Using a rock saw, rock samples were cut into small blocks and the weathered edges were removed. Rock powders were prepared by crushing the blocks in a steel jaw crusher and then powdered using a shatterbox with a tungsten carbide puck. The shatterbox puck and chamber were cleaned in between each crushing step using deionized water and ethanol. Clean quartz sand was run between each sample to prevent cross-contamination.

\subsection{Method 1: elemental analyzer mass spectrometry}

We analyzed all rock standards at the University of Washington Isolab facilities following Stüeken (2013). First, $\sim 1 \mathrm{~g}$ of each sample was weighed into a clean (baked at $500^{\circ} \mathrm{C}$ overnight) Pyrex test tube. Then, $\sim 10 \mathrm{~mL} 6 \mathrm{~N} \mathrm{HCl}$ was added, stirred with a glass stir rod, sonicated for $30 \mathrm{~min}$, and left in an oven set to $60^{\circ} \mathrm{C}$ over night to remove carbonate. Tubes were then centrifuged to settle suspended sediment, acid was decanted, fresh acid was added, and the samples were sonicated and dried a second time as above. This decarbonation was done once more. Subsequently, we rinsed samples three times in DI- $\mathrm{H}_{2} \mathrm{O}$, and all were dried for 3 days at $60^{\circ} \mathrm{C}$.

Between 12 and $150 \mathrm{mg}$ of decarbonated sample in $9 \times 5 \mathrm{~mm} \mathrm{Sn}$ capsules was flash combusted at $1000^{\circ} \mathrm{C}$ in a Costech ECS 4010 Elemental Analyzer with an excess of $\mathrm{O}_{2}$. Combustion products passed over a reduced copper column at $650{ }^{\circ} \mathrm{C}$ to convert all $\mathrm{N}$ to $\mathrm{N}_{2}$ and absorb excess $\mathrm{O}_{2}$ and a magnesium perchlorate trap to absorb water. Sample gas then passed through a $3 \mathrm{~m}$ gas chromatography column to separate $\mathrm{N}_{2}$ from $\mathrm{CO}_{2}$ before being analyzed on a Finnigan MAT253 continuous-flow isotope-ratio mass spectrometer via a ThermoFinnigan Conflo III. All analyses were quantified using IsoDat software. Errors reported are standard deviations from repeated analyses. We used the following isotopic standards: two glutamic acids (GA-1 and GA-2), dried salmon (SA), and an internal rock standard (McRae Shale).

\subsection{Method 2: colorimetry}

We followed the procedure outlined in Hall (1993) to analyze samples using colorimetry.

\subsubsection{Reagent list}

\section{КOH}

A $25 \%$ mass : volume solution of $\mathrm{KOH}$ was used for HFneutralizing. We dissolved $250 \mathrm{~g} \mathrm{KOH}$ in $1 \mathrm{~L}$ of water.

\section{Phenol reagent}

We weighed out $7.0 \mathrm{~g}$ of crystalline phenol and $0.02 \mathrm{~g}$ sodium nitroprusside into a $200 \mathrm{~mL}$ beaker. To this, we added $20 \mathrm{~mL}$ of $\mathrm{KOH}$ reagent and $60 \mathrm{~mL}$ of deionized water. Solids were stirred to dissolve, and then the solution was topped up to $100 \mathrm{~mL}$ total volume with DI- $\mathrm{H}_{2} \mathrm{O}$.

\section{$\mathrm{NaOCl}$}

We diluted $20 \mathrm{~mL}$ of commercially available $\mathrm{NaOCl}$ to $100 \mathrm{~mL}$ total volume with DI- $\mathrm{H}_{2} \mathrm{O}$.

\subsubsection{Stock solution and working standards}

A $1 \mathrm{~g} \mathrm{NH}_{4}^{+} \mathrm{L}^{-1}$ stock solution was prepared in a $250 \mathrm{~mL}$ volumetric flask by dissolving $0.7433 \mathrm{~g}$ of $\mathrm{NH}_{4} \mathrm{Cl}$ salt in $250 \mathrm{~mL}$ DI- $\mathrm{H}_{2} \mathrm{O}$. From this, a secondary ammonium standard solution of $0.2 \mathrm{~g} \mathrm{NH}_{4}^{+} \mathrm{L}^{-1}$ was prepared in a $100 \mathrm{~mL}$ volumetric flask using $20 \mathrm{~mL}$ of the ammonium stock solution, topped with DI- $\mathrm{H}_{2} \mathrm{O}$. The stock solution was diluted to make working standard solutions of $0.005,0.01,0.05,0.1$, and $0.2 \mathrm{~g} \mathrm{~L}^{-1}$, which were used to construct standard curves for sample concentration determination.

\subsubsection{Sample digestion}

Working standards, blanks (DI- $\left.\mathrm{H}_{2} \mathrm{O}\right)$, and rock powder were subjected to $\mathrm{HF}$ treatment at room temperature in $25 \mathrm{~mL}$ Teflon vials. To these vials, we added $2 \mathrm{~mL}$ of working standard, $2 \mathrm{~mL}$ of blank, or approximately $0.25 \mathrm{~g}$ of rock powder. The samples were digested for 7 days in $2 \mathrm{~mL}$ of $50 \%$ hydrofluoric acid in a fume hood. We swirled vials every 2 days to facilitate digestion.

After sample digestion period, the solution was neutralized by adding $20 \mathrm{~mL}$ of $25 \% \mathrm{KOH}$ to each vial. Exploratory analysis of different aliquots from the top, middle, and bottom of each vial gave different results; thus, the solution was stirred with a glass rod to ensure homogenization. The stir rod was rinsed with $\mathrm{DI}-\mathrm{H}_{2} \mathrm{O}$ in between samples to prevent cross-contamination. Homogenized solutions sat for $15 \mathrm{~min}$ to allow suspended rock powder to settle.

\subsubsection{Colorimetric analysis}

All liquid, plus undissolved solids, were placed in a $100 \mathrm{~mL}$ round bottom flask, which was attached to a standard distillation setup. Samples were boiled for $\sim 10$ to $15 \mathrm{~min}$, and $8 \mathrm{~mL}$ of distillate was collected into $8 \mathrm{~mL}$ of $0.01 \mathrm{~N} \mathrm{H}_{2} \mathrm{SO}_{4}$. To this, $1 \mathrm{~mL}$ of phenol reagent, $1 \mathrm{~mL}$ of $\mathrm{NaOCl}$, and $5 \mathrm{~mL}$ DI- $\mathrm{H}_{2} \mathrm{O}$ were added and stirred. The colour-change reaction was allowed to proceed for $2 \mathrm{~h}$. Absorbance was measured at $630 \mathrm{~nm}$ in a plastic cuvette on an Ocean Optics spectrophotometer and quantified using SpectraSuite software.

Standard solutions were processed the same way as the samples. We made a standard curve of absorbance plotted 
against starting concentration $(0.005,0.01,0.05,0.1$, and $0.2 \mathrm{~g} \mathrm{~L}^{-1}$ ) of standard solutions. This was used to calculate sample concentrations, applying appropriate dilution corrections.

\subsection{Method 3: fluorometry}

The following is a detailed description of our adaptation of the Holmes et al. (1999) method. Key considerations and suggestions for improvement are discussed in the following section.

\subsubsection{Reagent list}

\section{Working reagent $(\mathrm{WR})$}

We made a mixture of sodium sulfite, borate buffer, and orthophthaldialdehyde (OPA) solutions. The procedure for preparing the working reagent follows Holmes et al. (1999). To make the sodium sulfite solution, $0.2 \mathrm{~g}$ of sodium sulfite was added to $25 \mathrm{~mL}$ of DI- $\mathrm{H}_{2} \mathrm{O}$. For the borate buffer, $80 \mathrm{~g}$ of sodium tetraborate was added to $2 \mathrm{~L}$ of $\mathrm{DI}-\mathrm{H}_{2} \mathrm{O}$, which was then stirred for $4 \mathrm{~h}$ with a stir bar. To make the OPA solution, $4 \mathrm{~g}$ of OPA was added to $100 \mathrm{~mL}$ of $95 \%$ ethanol and protected from the light while stirred with a stir bar. The borate buffer, OPA solution and $10 \mathrm{~mL}$ of the sodium sulfite were mixed in a $>2 \mathrm{~L}$ brown polyethylene bottle. The working reagent mixture sat for at least 1 day prior to use.

\subsubsection{Stock solution and working standards}

The same stock solution was used for fluorometry as for colorimetry. A range of working standards was made by diluting stock solution $\left(0.2 \mathrm{~g} \mathrm{NH}_{4}^{+} \mathrm{L}^{-1}\right)$ into reaction bottles, resulting in concentrations of $0.005,0.01,0.05$, and $0.1 \mathrm{~g} \mathrm{NH}_{4}^{+} \mathrm{L}^{-1}$. This range of working standards was used to construct standard curves.

\subsubsection{Sample digestion}

The same digestion and neutralization procedures were used for fluorometry as for colorimetry.

\subsubsection{Optional distillation}

Some replicates of samples were distilled, as described in Sect. 2.4. As this step is the most time-intensive step aside from digestion, we ran most analyses without distilling. As discussed later, this step may be useful for samples with either low $\mathrm{N}$ or samples that are difficult to digest completely (e.g., G2).

\subsubsection{Fluorometric analysis}

Brown $50 \mathrm{~mL}$ polyethylene bottles were used for the fluorescing reaction. The reaction bottles were first emptied of their storage solution (i.e., clean working reagent) and rinsed with $5 \mathrm{~mL}$ DI- $\mathrm{H}_{2} \mathrm{O}$. Using a pipette, $10 \mathrm{~mL}$ of DI- $\mathrm{H}_{2} \mathrm{O}$ was added to each reaction bottle. Subsequently, an aliquot of the neutralized solution was added. About $0.1 \mathrm{~mL}$ of sample solution was added to each bottle. Then, $2.5 \mathrm{~mL}$ of working reagent was added to each reaction bottle. After adding the working reagent, the reaction bottle was inverted to homogenize the sample.

Immediately after homogenization, an aliquot of solution from the reaction bottle was transferred to a plastic cuvette, and fluorescence was measured in a $1 \mathrm{~cm}$ plastic cuvette using a Turner Designs AquaFluor fluorometer. The fluorometer has a $350 \mathrm{~nm}$ excitation filter with a $25 \mathrm{~nm}$ bandpass, $\mathrm{a} \geq 420 \mathrm{~nm}$ emission filter, and a minimum detection limit of $0.1 \mu \mathrm{M} \mathrm{NH}+$. After this initial measurement, the aliquot of solution was transferred back into its reaction bottle, the cuvette was rinsed, and the bottle was capped and inverted several times to homogenize the sample. The sample then reacted for $3 \mathrm{~h}$. After $3 \mathrm{~h}$, fluorescence was measured in three sample aliquots. Sample concentrations were calculated using a standard curve (Fig. 1).

After measurement, the remaining solution in the reaction bottle was emptied and a small amount $(\sim 2 \mathrm{~mL}$ each) of working reagent and DI- $\mathrm{H}_{2} \mathrm{O}$ was added to the bottles for storage.

\subsubsection{Calculation of sample $\mathrm{NH}_{4}$ concentration}

Net fluorescence $\left(F_{\text {net }}\right)$ for working standards and samples were calculated by averaging the three final fluorescence $(\bar{F})$ readings, subtracting initial fluorescence $\left(F_{i}\right)$, and then subtracting average fluorescence minus initial from the blank $(\bar{B}$; Eq. 1).

$F_{\text {net }}=\bar{F}-F_{i}-\bar{B}$

Then, using standard curves (either corrected to digestion vials or in reaction bottles; slope $=s$ ), sample concentration in either digestion vials or reaction bottles was calculated. Importantly, we chose to force standard curves through the origin.

Final $\mathrm{NH}_{4}^{+}$concentrations $\left(\left[\mathrm{NH}_{4}^{+}\right]\right)$were calculated by correcting concentration to the $\mathrm{KOH}$-neutralized vial, multiplying concentration by total volume in the vial $(D)$ to determine a mass of $\mathrm{NH}_{4}^{+}$. Then, we divided this $\mathrm{NH}_{4}^{+}$mass by starting sample rock powder mass $(\mathrm{m})$ to get the concentration of $\mathrm{NH}_{4}^{+}$in parts per million mass (Eq. 2).

$\left[\mathrm{NH}_{4}^{+}\right]=\frac{F_{\text {net }}}{s} \frac{D}{m}$

\section{Results}

\subsection{Method 1: mass spectrometry}

Elemental analyzer mass spectrometry was able to measure $\mathrm{N}$ concentration in all rock standards (Table 2). Analyses for 
Table 2. Nitrogen and $\delta^{15} \mathrm{~N}$ data from colorimetric and mass spectrometry analyses. Both techniques appear to underestimate $\mathrm{N}$ concentration, perhaps due to incomplete $\mathrm{N}$ extraction during combustion for mass spectrometry or incomplete recovery of $\mathrm{NH}_{4}^{+}$during distillation. Concentrations are in parts per million.

\begin{tabular}{lrrrr}
\hline Standard & Published & Colorimetric & $\begin{array}{r}\text { Mass } \\
\text { spectrometry }\end{array}$ & $\delta^{15} \mathrm{~N}$ \\
\hline BCR-1/2 & $34 \pm 12$ & $12.6 \pm 8$ & 21 & $1.05 \pm 0.4$ \\
BHVO-2 & $22.6 \pm 3$ & $3.5 \pm 0.7$ & $13.3 \pm 0.6$ & $-0.3 \pm 0.2$ \\
G-2 & $34 \pm 4$ & $1.6 \pm 0.9$ & $5 \pm 0.7$ & $1.23 \pm 1.32$ \\
SY-4 & & $6.9 \pm 2.8$ & $14.3 \pm 0.6$ & $2.13 \pm 0.5$ \\
LKSD-4 & & $487 \pm 401$ & $16000 \pm 8$ & $3.59 \pm 0.1$ \\
Till-4 & & $82.2 \pm 40$ & $440 \pm 2$ & $6.33 \pm 0.1$ \\
Carb & & 66.1 & $48.5 \pm 1.3$ & \\
\hline
\end{tabular}

crystalline standards are lower than published values, likely due to the incomplete liberation of $\mathrm{N}$ from silicate lattices during combustion (Bräuer and Hahne, 2005). Values for BCR-1/2 are $62 \%$ of published values, BHVO-2 $59 \%$ of published values, and G-2 $15 \%$ of published values. Values reported herein for Till-4, SY-4, and LKSD-4 are the first to our knowledge.

In addition, we report $\delta^{15} \mathrm{~N}$ values for all samples (Table 2). While more analyses would need to occur for these to be used as isotopic standards, the fact that there is measurable $\mathrm{N}$ in all standards suggests they may be suitable candidates for geologic $\mathrm{N}$-isotopic standards. Samples with high $\mathrm{N}$ (presumably some organic N), LKSD-4, and Till-4, could be ideal.

\subsection{Method 2: colorimetry}

The colorimetric method was able to analyze all rock standards (Table 2), with standard curves having $r^{2}$ values above 0.99 (Fig. 1). Measured concentrations are lower than published values: at 37,15 , and $5 \%$ of published values for BCR-2 , BHVO-2, and G-2, respectively (Table 2). We suggest that this potential underestimate is due, in part, to difficulty in quantitatively distilling all $\mathrm{NH}_{4}^{+}$from a dissolved sample. The distillation apparatus is imprecise in nature, and controlling the final volume of distillate is difficult.

\subsection{Method 3: fluorometric method}

\subsubsection{Rock standards}

Results for rock standard analyses are shown in Table 3. Values range from 5.2 to $5200 \mathrm{ppm}$ by mass. Analyses without distillation match published values within error for BCR-2 and BHVO-2, with values of $33 \pm 8.3$ and $15 \pm 5.7 \mathrm{ppm}$, compared to $34 \pm 12$ and $22.6 \pm 3$, respectively. Analyses of $\mathrm{G}-2$ are lower than published, at $11 \pm 4.9$ from our analyses and $34 \pm 4$ from literature values. Other standards have values of $5.2 \pm 4.5$ (SY-4), $5200 \pm 1000$ (LKSD-4), and

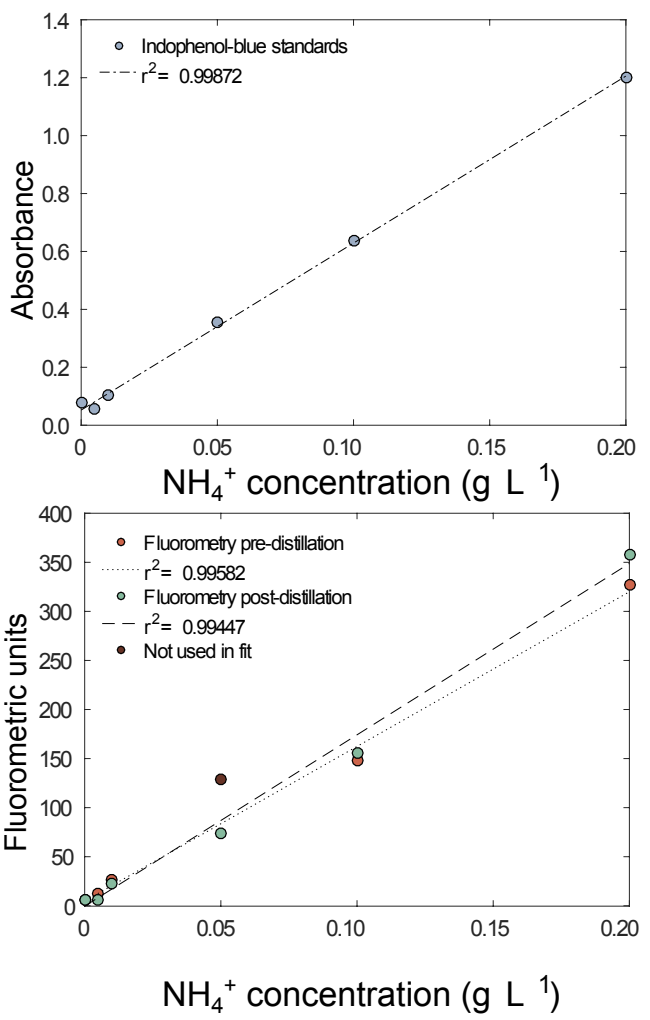

Figure 1. Example standard curves for colorimetry and fluorometry analyses. Absorbance is the fraction of incoming light that is absorbed by the indophenol-blue solution. The value larger than 1 for $0.20 \mathrm{~g} \mathrm{~L}^{-1}$ is due to dilution for absorbance reading and correction for this dilution. These standard curves were used to calculate sample values for those analyses occurring after distillation. In addition, fluorometry curves show that distillation does not greatly affect working standards, though the same may not be true for actual samples.

$71 \pm 25$ ppm (Till-4). Analyses after distillation are generally higher than those with no distillation step.

\subsubsection{Continental crust}

Measured $\mathrm{NH}_{4}^{+}$concentrations from a number of continental crust samples are shown in Table 4 . We have included analyses of BCR-2 in the "volcanics" category. In general, samples of all crystalline rock types have between 10 and $40 \mathrm{ppm}$, and sedimentary rocks are higher, with values between 100 and $1000 \mathrm{ppm}$. 

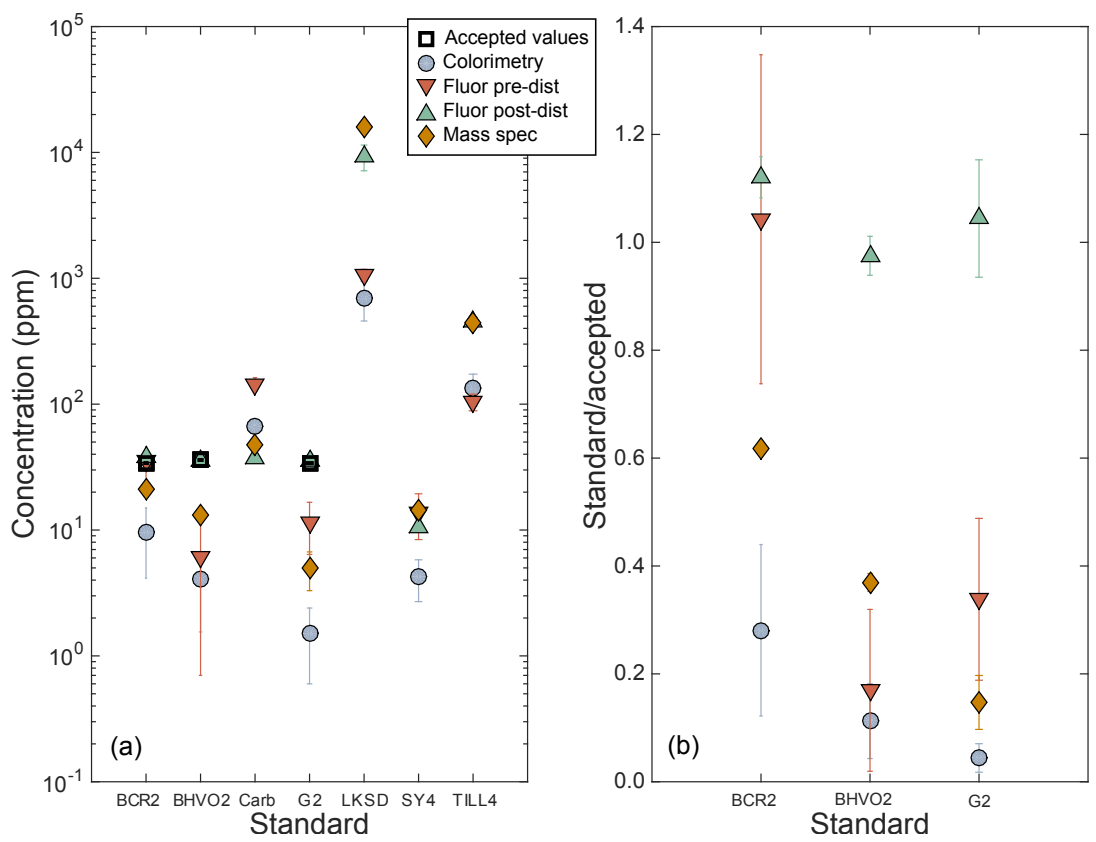

Figure 2. (a) Comparison of $\mathrm{N}$ concentrations in rock standards from three different methods. Colorimetry consistently yields lower values than fluorometry, and values are typically lower than EA mass spectrometry. Fluorometry and EA mass spectrometry give similar results for sedimentary rocks (LKSD-4, Till-4, 5.1) but tend to differ for crystalline rocks (BCR-2, BHVO-2, SY-4, G-2), with fluorometry giving higher concentrations. (b) Though associated errors are larger, fluorometry does reproduce published $\mathrm{N}$ concentration values from three standards (BCR-2, BHVO-2, G-2), especially after distillation. The legend is the same in both (a) and (b).

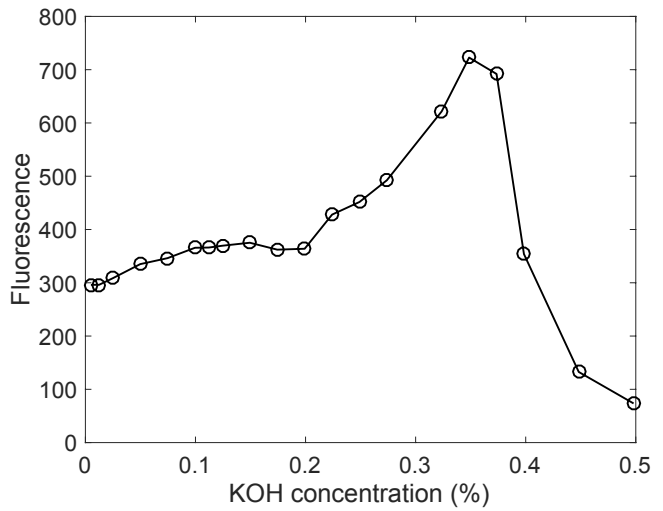

Figure 3. Sensitivity test for samples with $0.010 \mathrm{~g} \mathrm{~L}^{-1} \mathrm{NH}_{4}^{+}$and varying concentrations of $\mathrm{KOH}$ in reaction bottles. $\mathrm{KOH}$ clearly has an effect on fluorescence. Fluorescence values are consistent between 0 and $0.2 \% \mathrm{KOH}$, with a large increase approaching $0.35 \%$ $\mathrm{KOH}$ and a steep drop-off at higher $\mathrm{KOH}$ concentrations. We suggest that high concentrations of $\mathrm{KOH}$ overwhelm the buffering capacity of the working reagent and inhibit the completion of the fluorescing reaction. All reported runs herein had between 0.05 and $0.2 \% \mathrm{KOH}$. Controlling $\mathrm{KOH}$ concentration is a key factor in the success of this method.

\section{Discussion}

\subsection{Fluorometry}

\subsubsection{Reproducibility and reproduction of published values}

Reproducibility of repeated analysis was between 10 and $50 \%$ of mean values for all rock standards (Table 3). Overall, error appears to be lowest for samples which are most easily digested: BCR-2 and carbonate. More felsic standards, such as G-2, have higher error but also show lower concentrations than previous work. On runs with distillation, G-2 (36 \pm $4 \mathrm{ppm})$ matched published values ( $34 \pm 4 \mathrm{ppm})$, BCR-1/2 $(38 \pm 1 \mathrm{ppm})$ also matched published values $(34 \pm 12 \mathrm{ppm})$, and BHVO-2 $(35 \pm 1 \mathrm{ppm})$ had higher than published values $(22.6 \pm 3 \mathrm{ppm})$. Runs without distillation gave concentrations below their published values, with $11 \pm 4.9 \mathrm{ppm}$ for G-2 and $15 \pm 5.7$ for BHVO-2. Therefore, distillation appears to improve agreement between fluorometry and NAA, though this may be coincidence, as NAA analysis has several unresolved issues with calculation accuracy.

We stress that although NAA is of appropriate sensitivity to measure parts per million level $\mathrm{N}$ concentrations (e.g., Kolesov, 1995), there are complicating issues. Neutron bombardment can also create ${ }^{14} \mathrm{C}$ via reaction with ${ }^{17} \mathrm{O}$, with a theoretical apparent $\mathrm{N}$ contribution in a sample with $40 \%$ $\mathrm{O}$ of $18 \mathrm{ppm}$, though analysis of a synthetic $\mathrm{Al}_{2} \mathrm{O}_{3}$ doped 


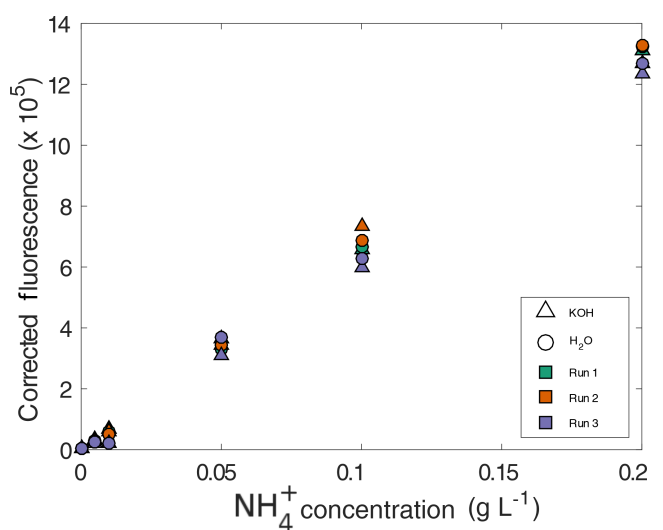

Figure 4. Standard curves from three different days comparing preparations made with $\mathrm{KOH}$ solutions to those with only water. Since curves from the same day are indistinguishable with and without $\mathrm{KOH}$, the fluorescing reaction is not affected by the presence of $\mathrm{KOH}$ (see text for details). Some variability exists between runs, especially at lower concentrations, but variations are small compared to changes in fluorescence units with changing concentration.

with $20 \%{ }^{17} \mathrm{O}$ suggests the actual effect may only be $6 \mathrm{ppm}$ (Shukla et al., 1978). In addition, 52 analyses of BCR-1 by Murty et al. (1983) yielded a range in concentration from 15 to $62 \mathrm{ppm}$. The authors suggest this is due to heterogeneous distribution of $\mathrm{N}$ in $\mathrm{BCR}-1$. Alternately, such a range in concentration could be due to adsorption of atmospheric $\mathrm{N}_{2}$. Though sample powders are prepared for irradiation after vacuum pumping (or heating), the possibility of atmospheric $\mathrm{N}_{2}$ contamination appears unresolved (Norris and Schaeffer, 1982). Thus, though NAA analyses of $\mathrm{N}$ in rock standards should be able to quantify total $\mathrm{N}$ in a sample, several outstanding issues prevent concentrations reported in the literature from being accepted as geochemical standards. A major difficulty in the development of new techniques for measuring geologic $\mathrm{N}$ is a lack of international standards.

\subsubsection{Effects of $\mathrm{KOH}$}

The most significant parameter affecting the quality of the standard curves was the concentration of $\mathrm{KOH}$ in the reaction bottles. For a given concentration of $\mathrm{NH}_{4}^{+}$, varying $\mathrm{KOH}$ concentration altered resulting fluorometry readings (Fig. 3). Since the fluorescing reaction is $\mathrm{pH}$ dependent (operating between $\mathrm{pH} 8$ and 10 due to borate buffer), the addition of excess $\mathrm{KOH}$ causes the $\mathrm{pH}$ of the solutions to be too high and the fluorescing reaction to be inhibited. We adjusted sample dilutions and volumes to result in $\mathrm{KOH}$ concentrations in reaction bottles of between 0.05 to $0.2 \%$.

We have verified that small $\mathrm{KOH}$ concentrations, as described above, do not affect standard curves (Fig. 4). Curves prepared on multiple days with water were identical to those produced with $\mathrm{KOH}$, indicating that the fluorescing reaction had gone to completion. High corrected fluorescence values

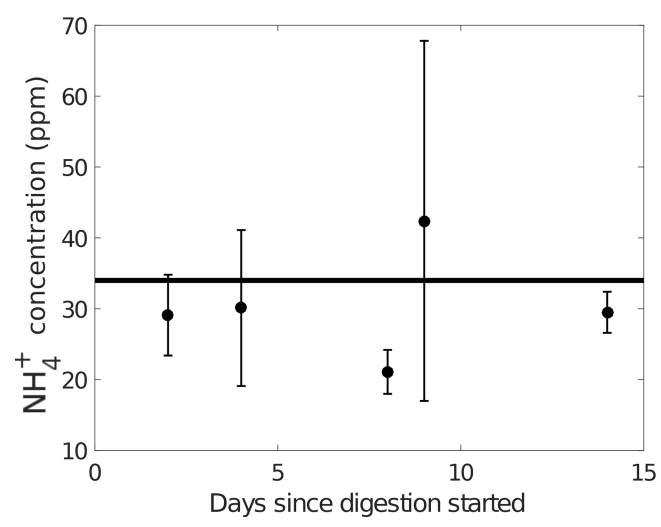

Figure 5. Digestion length test for BCR-2 by the fluorometry technique. Samples were digested in $2 \mathrm{~mL} 50 \% \mathrm{HF}$ for the number of days indicated. Analyses reproduce published value (34 ppm, black line) within error after only 2 days and, aside from one analysis 8 days after digestion began, approximate this value afterwards. There is large error in some samples compared to Table 3, likely due to the increased number of analyses reported in Table 3 , decreasing standard deviation.

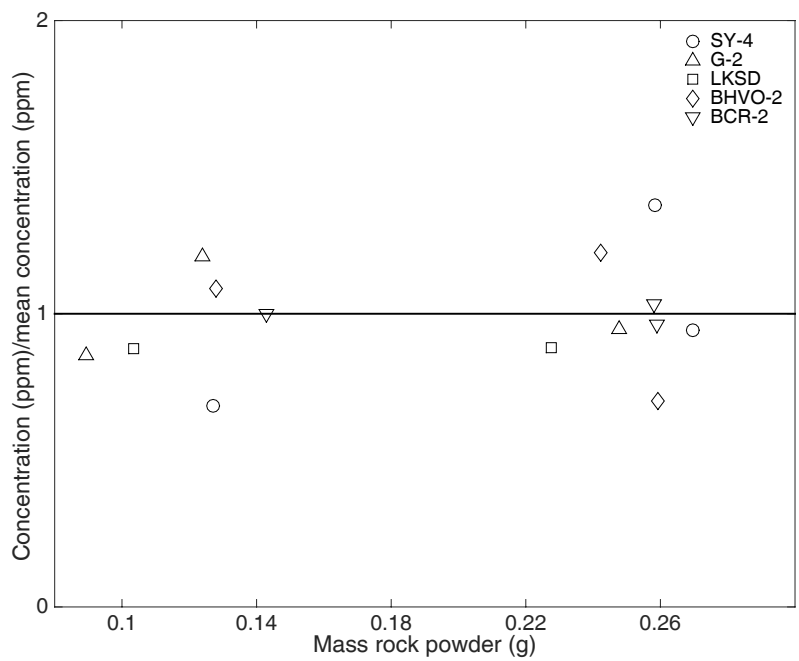

Figure 6. Measured concentration for rock standards normalized to mean concentration from analysis day plotted against the mass rock powder. Symbols represent standards, and all analyses shown are fluorometry with and without distillation. Decreasing initial sample mass does not seem to affect the concentrations calculated, as measured concentrations show no significant trend away from the mean value given the different amounts of rock powder dissolved.

were due to corrections for dilutions occurring when $\mathrm{KOH}$ was added to the initial standard volume, as well as dilutions occurring when preparing reaction bottles. Though there is some variability at concentrations below $0.020 \mathrm{~g} \mathrm{~L}^{-1}$ from day to day, the similarity of $\mathrm{KOH}$ curves and water-only curves implies that the standard curve technique is viable. 
Table 3. Nitrogen from all three techniques (mass spectrometry, colorimetry, and fluorometry) compared to published values from NAA. Shown is the mean with standard deviation and coefficient of variation in parentheses. The values after the commas in the Fluorometry column represent the number of separate measurements for non-distilled samples. All concentrations are in parts per million.

\begin{tabular}{lrrrrr}
\hline Standard & Published & Colorimetric & Mass spectrometry & Post-distillation & Fluorometry \\
\hline BCR-1/2 & $34 \pm 12(0.35)$ & $12.6 \pm 8(0.63)$ & 21 & $38 \pm 1(0.02)$ & $33 \pm 8.3(0.25), 36$ \\
BHVO-2 & $22.6 \pm 3(0.13)$ & $3.5 \pm 0.7(0.2)$ & $13.3 \pm 0.6(0.05)$ & $35 \pm 1(0.03)$ & $15 \pm 5.7(0.38), 9$ \\
G-2 & $34 \pm 4(0.12)$ & $1.6 \pm 0.9(0.56)$ & $5 \pm 0.7(0.14)$ & $36 \pm 4(0.11)$ & $11 \pm 4.9(0.45), 13$ \\
SY-4 & & $6.9 \pm 2.8(0.41)$ & $14.3 \pm 0.6(0.04)$ & $11 \pm 1(0.09)$ & $5.2 \pm 4.5(0.87), 9$ \\
LKSD-4 & & $487 \pm 401(0.82)$ & $16000 \pm 8(<0.01)$ & $9300 \pm 2150(0.23)$ & $5200 \pm 1000(0.19), 9$ \\
Till-4 & & $82.2 \pm 40(0.49)$ & $440 \pm 2(<0.01)$ & $455 \pm 36(0.08)$ & $71 \pm 25(0.35), 15$ \\
Carb & & 66.1 & $48.5 \pm 1.3(0.03)$ & 37 & $93 \pm 18(0.19), 12$ \\
\hline
\end{tabular}

Table 4. Nitrogen concentration (ppm) in upper-crustal rocks using the fluorometry method.

\begin{tabular}{lrrr}
\hline Rock type & Mean \pm SD & $\begin{array}{c}\text { Coefficient } \\
\text { of variation }\end{array}$ & $\begin{array}{r}\text { No. } \\
\text { samples }\end{array}$ \\
\hline Tills & $81.2 \pm 36.4$ & 0.45 & 8 \\
Silt & $1060 \pm 113$ & 0.11 & 1 \\
Volcanics & $21.4 \pm 12.5$ & 0.11 & 13 \\
Carbonates & $114.2 \pm 40.9$ & 0.36 & 1 \\
Granitic & $15.8 \pm 14.6$ & 0.92 & 5 \\
Gabbro & $11.3 \pm 12.6$ & 1.12 & 5 \\
Gneiss & $29.8 \pm 0.8$ & 0.03 & 1 \\
Xenolith & $34.4 \pm 16.1$ & 0.47 & 8 \\
Acasta & $6.2 \pm 1.3$ & 0.20 & 1 \\
\hline
\end{tabular}

\subsubsection{Digestion length}

As sample digestion is only partial, it is possible that the length of digestion has an effect on final concentration readings. We conducted a digestion length test for BCR-2 (Fig. 5) and found no clear relationship between digestion length and calculated $\mathrm{N}$ concentration. It appears as though there are other factors that have a greater effect on $\mathrm{N}$ concentration. Determining the length of time needed for the extraction of all $\mathrm{NH}_{4}^{+}$would be an important step, as this could increase sample processing efficiency and sample throughput.

\subsection{Methods comparison: pros and cons}

The main difference between methods discussed in this work is that two (mass spectrometry and NAA) analyze total N, while colorimetry and fluorometry specifically target $\mathrm{NH}_{4}^{+}$ (Table 5). While assaying total $\mathrm{N}$ may be advantageous in samples with mixed $\mathrm{N}$ speciation (e.g., sedimentary rocks), total $\mathrm{N}$ analysis has a more difficult time accounting for $\mathrm{N}_{2}$ contamination from the atmosphere. As rock samples are commonly ground to a fine powder before analysis, the possibility of adsorbing some $\mathrm{N}_{2}$ could affect the accuracy of total $\mathrm{N}$ methods, especially where mineral-bound $\mathrm{N}$ concentrations are low. Targeted analysis of $\mathrm{NH}_{4}^{+}$is likely more bet- ter suited to crystalline rocks, where $\mathrm{NH}_{4}^{+}$is the primary $\mathrm{N}$ species.

Mass spectrometry has the major advantage over fluorometry or colorimetry by being able to measure $\mathrm{N}$ isotopes in a given sample. Isotopic values are crucial in determining $\mathrm{N}$ cycling, both biologically and in geologic reservoirs. One application of the fluorometry technique is as a "first-pass" analysis to determine $\mathrm{N}$ concentration. The concentration of $\mathrm{N}$ in a sample dictates what type of mass spectrometric technique (e.g., EA, offline combustion, etc.) is most appropriate for isotopic analysis.

Given the expense of installing a mass spectrometer, the relative inaccessibility of neutron irradiation sources, and the time required for NAA (weeks to months), fluorometry presents a relatively quick and straightforward alternative. All equipment and reagents are easily obtainable. Fluorometers are much more affordable (USD 3000 to 10000) than mass spectrometers (hundreds of thousands of US dollars) and do not require any supporting infrastructure and maintenance is comparatively low. And while the technique in its current state may not fully liberate $\mathrm{NH}_{4}^{+}$in all samples, it performs with similar reproducibility to mass spectrometry and NAA. Fluorometry also performs well without distillation, required for colorimetry. Distillation takes 15-20 min per sample, limiting throughput, and makes either fluorometry or colorimetry more on par with mass spectrometry in terms of time needed for analyses. Additionally, it is difficult to consistently distill the same volume for each sample, which limits accuracy and reproducibility.

In regards to fluorometric reagents needed, while HF is extremely dangerous, it is more commonly used in geochemistry than any of the colorimetric reagents (especially phenol and sodium nitroprusside), and with appropriate training and caution, it can be handled safely. Additional fluorometric reagents are less hazardous than colorimetric reagents and are linked with fewer long-term exposure issues.

The fluorometry technique also has the potential to measure very small quantities of $\mathrm{NH}_{4}^{+}$. Its original development was for measuring parts per billion level concentrations in natural waters, so if extraction from silicates can be com- 
Table 5. Comparison of different method requirements and performance. SPAD stands for samples per analysis day and indicates approximate number of samples that can be run in 1 day, after all prep work has been completed. Accessibility is a qualitative measure of how common analytical equipment is in the geochemical community. Reproducibility is the average of the coefficient of variation from Table 3 . Sensitivity indicates minimum concentration able to be potentially measurable.

\begin{tabular}{|c|c|c|c|c|}
\hline & Colorimetric & EA mass spectrometry & Fluorometry & NAA \\
\hline Prep time required & 1 week digestion & 1 week & 1 week digestion & weeks to months \\
\hline SPAD & $<30$ & 18 & $\begin{array}{l}50, \text { or }<30 \\
\text { with distillation }\end{array}$ & \\
\hline Species measured & $\mathrm{NH}_{4}^{+}$ & $\begin{array}{l}\text { easily combusted } \\
\text { organic, some } \mathrm{NH}_{4}^{+}\end{array}$ & $\mathrm{NH}_{4}^{+}$ & total \\
\hline Accessibility of equipment & high & medium & high & low \\
\hline Reproducibility & 0.52 & 0.05 & $0.38,0.09$-distilled & 0.2 \\
\hline Sensitivity & $\sim 5 \mathrm{ppm}$ & $\sim$ tens of ppm & $\mathrm{ppb}$ & ppm \\
\hline Reagent toxicity & HF high & low & HF high & radioactivity \\
\hline
\end{tabular}

Table 6. Nitrogen concentration in upper and lower-crustal rocks based on Wedepohl (1995). Proportions are of upper or lower-crust mass; $\mathrm{N}$ concentration (ppm) is from this study (where error is shown) or from Johnson and Goldblatt (2015) (JandG). Nitrogen contribution is simply concentration multiplied by the proportion of crust. We use gneisses as a proxy for felsic granulites and xenoliths for mafic granulites. Values from Johnson and Goldblatt (2015) are given for comparison, with error shown as standard error of the mean.

\begin{tabular}{|c|c|c|c|c|}
\hline Rock type & $\begin{array}{r}\text { Proportion } \\
\text { of crust (\%) }\end{array}$ & $\mathrm{N}(\mathrm{ppm})$ & $\mathrm{N}$ contribution & JandG \\
\hline \multicolumn{5}{|c|}{ Upper crust } \\
\hline Shale/silt & 6.16 & $1064 \pm 113$ & $65.6 \pm 7.0$ & $860 \pm 64$ \\
\hline Sandstone & 2.94 & 230 & 6.8 & $230 \pm 110$ \\
\hline Volcanics & 2.80 & 21. \pm 12.54 & $0.6 \pm 0.3$ & $50 \pm 60$ \\
\hline Carbonates & 1.96 & $114.2 \pm 40.9$ & $2.2 \pm 0.8$ & $130 \pm 17$ \\
\hline Granitic & 45 & $15.8 \pm 14.6$ & $7.1 \pm 6.6$ & $54 \pm 7$ \\
\hline Tonalite & 5 & 24 & 1.2 & $24 \pm 7$ \\
\hline Gabbro & 6 & $11.3 \pm 12.6$ & $0.7 \pm 0.8$ & $5 \pm 2$ \\
\hline Gneisses & 19.20 & $29.8 \pm 0.8$ & $5.7 \pm 0.2$ & $135 \pm 50$ \\
\hline Mica schist & 4.80 & 500 & 24.0 & $500 \pm 44$ \\
\hline Amphibolites & 5.40 & 22 & 1.2 & $22 \pm 10$ \\
\hline Marble & 1 & 1000 & 9.0 & $1000 \pm 500$ \\
\hline Total average & & & $124 \pm 6.7$ & $150 \pm 12$ \\
\hline \multicolumn{5}{|c|}{ Lower crust } \\
\hline Felsic granulites & 62 & $29.8 \pm 0.8$ & $18.4 \pm 0.5$ & $17 \pm 6$ \\
\hline Mafic granulites & 38 & $27.3 \pm 16.6$ & $13.1 \pm 6.1$ & $17 \pm 6$ \\
\hline Total average & & & $31.5 \pm 3.1$ & $17 \pm 6$ \\
\hline
\end{tabular}

plete, there is no reason to think a similar level of precision could not be developed for geologic samples.

\subsection{Suggestions for fluorometry improvement}

The most difficult to quantify aspect of the fluorometry and colorimetric methods are the efficiency of the extraction of $\mathrm{NH}_{4}^{+}$during HF digestion. Since HF digestion is only partial, assessing the amount of $\mathrm{NH}_{4}^{+}$that remains in undigested materials could prove valuable. Undigested materials are likely predominantly organics and/or oxides. Oxides should have low $\mathrm{NH}_{4}^{+}$, as there are no crystallographic spaces in mineral lattices to accommodate $\mathrm{NH}_{4}^{+}$. Organic content is typically low in crystalline rocks (e.g., granites, gneisses) but would contribute $\mathrm{N}$ to bulk rock concentrations. Minimizing the amount of rock sample powder used may increase the efficiency of extraction. Indeed, preliminary tests suggest that measured concentrations are not affected down to the initial rock powder mass of $0.1 \mathrm{~g}$ (Fig. 6), though at very small sample sizes homogeneity issues could become apparent.

Determining the concentration of $\mathrm{N}$ in non-dissolved material could be another area for improvement. The OPA 
Table 7. Total continental crust $\mathrm{N}$ based on tills, rock proportions, and xenolith concentrations. Our results are consistent with previous work that suggests there is about $2 \times 10^{18} \mathrm{~kg} \mathrm{~N}$ in the continental crust. All $\mathrm{N}$ masses are $10^{18} \mathrm{~kg}$.

\begin{tabular}{lrrr}
\hline & & & \\
Reservoir & Mass in kg $(\%$ of total $)$ & $\mathrm{N}(\mathrm{ppm})$ & N mass \\
\hline Upper crust (tills) & $1.01 \times 10^{22}(53 \%)$ & $81.2 \pm 36.4$ & $0.82 \pm 0.4$ \\
Upper crust (rock abundance) & $1.01 \times 10^{22}(53 \%)$ & $124 \pm 6.7$ & $1.25 \pm 0.06$ \\
Lower crust & $8.9 \times 10^{21}(47 \%)$ & $28.9 \pm 6.8$ & $0.26 \pm 0.06$ \\
Total crust (till + lower) & $1.9 \times 10^{22}$ & $57 \pm 22$ & $1.1 \pm 0.4$ \\
Total crust (abundance + lower) & $1.9 \times 10^{22}$ & $78 \pm 7$ & $1.48 \pm 0.1$ \\
\hline
\end{tabular}

reagent is sensitive to amino acids in addition to $\mathrm{NH}_{4}^{+}$; the addition of sodium sulfite destroys the sensitivity to amino acids, making OPA react with ammonium alone (Holmes et al., 1999). If residual material left after HF dissolution were dissolved with an acid that dissolves organic matter (e.g., $\mathrm{H}_{2} \mathrm{SO}_{4}$ ), one could carry out a fluorometric analysis using a working reagent without sodium sulfite to constrain non-silicate $\mathrm{N}$ content.

There are other small areas for fluorometry improvement. One is to filter samples after neutralizing with HF, as sediment may affect fluorescence readings. The second is to attempt a neutralizing agent other than $\mathrm{KOH}$, which may contain trace levels of $\mathrm{NH}_{4}^{+}$. $\mathrm{KOH}$ was used initially due to its better performance during distillation (Hall, 1993).

As noted by Ader et al. (2016), acquisition and development of a robust international standard would be extremely helpful in this or any future analytic technique development. Our work demonstrates that existing rock standards may be suited to this charge.

\subsection{Preliminary application - continental crust}

As a demonstration of the potential of the method, we calculated a $\mathrm{N}$ budget of the continental crust using analyses of a variety rock types. Most samples have come from Canada (Sevigny et al., 1990; Larocque and Canil, 2010; Canil and Lacourse, 2011), though several are from other areas of North America. We present only averages here; full analyses are available in the Supplement. In addition, we have measured the $\mathrm{N}$ concentration in samples of the Acasta Gneiss and found it to be $6.2 \pm 1.3 \mathrm{ppm}$ (Table 4). The Acasta Gneiss is currently the oldest widely accepted rock on Earth and may be a remnant of processing by plate tectonics or at least crustal recycling (Roth et al., 2014). We do not include it in our calculations of continental crust, however, since it may not be representative of "typical" continental crust.

We calculate the $\mathrm{N}$ content of the upper continental crust using two approaches. The first is to use glacial tills as an average of upper-crustal rocks (Tables 4, 6). Again, this should be regarded as a proof of concept approach, as these tills are all from British Columbia, Canada, and primarily erode Phanerozoic rocks. The second method relies on rock abun- dance data after Wedepohl (1995) and measured $\mathrm{N}$ in those rocks either from this study (Tables 4,6 ) or as compiled in Johnson and Goldblatt (2015). We stress that while tills are used as a representative of the upper crust, analyses of other rocks are not meant to be representative and are instead analyzed to fill in gaps in poorly characterized reservoirs (e.g., volcanic, middle-crustal xenoliths).

The two upper-crust approaches yield results that are distinct from each other (Tables 4, 7). The rock abundance approach is most similar to Johnson and Goldblatt (2015). A wider range of till samples, which have eroded a greater variety of crustal ages and rock types, could address this discrepancy.

In addition, we use xenolith data to approximate the mafic lower crust and gneisses to approximate the felsic lower crust. These results are quite exploratory, and further analysis of lower-crustal samples would assist interpretation greatly. By combining our lower-crustal estimate with upper-crust estimates, we find total-crust $\mathrm{N}$ to be $1.1 \pm 0.4 \times 10^{18} \mathrm{~kg}$ using the till + xenolith approximation and $1.48 \pm 0.1 \times 10^{18} \mathrm{~kg}$ using rock proportion+xenolith. While these are the same within error, we note that this is primarily due to "diluting" the upper-crust estimates with lower-crustal values.

As an exercise to assess the impact of uncertainty in fluorometry measurements, we can perform the same budget calculations by using the highest and lowest analyzed values of BCR-2 compared to the mean value to bracket calculation accuracy. Given a maximum measured value of $42 \mathrm{ppm}$ and a minimum measured value of $21 \mathrm{ppm}$ (Supplement), compared to a mean of $33 \mathrm{ppm}$ for BCR-2, we can assess the effect of multiplying continental budgets by 1.3 and 0.64 . This leads to a till-based upper-crust range of $0.5 \times 10^{18}$ to $1.1 \times 10^{18} \mathrm{~kg} \mathrm{~N}$, a rock-abundance-based upper-crust range of 0.8 to $1.7 \times 10^{18} \mathrm{~kg} \mathrm{~N}$, and a lower crust of 0.2 to $0.4 \times 10^{18} \mathrm{~kg} \mathrm{~N}$. These differences in continental $\mathrm{N}$ budget estimates do not change the broad agreement of our proof of concept budget with previously published work, i.e., that the continental crust contains $\sim 0.5$ present atmospheric mass of $\mathrm{N}\left(\mathrm{PAN}=4 \times 10^{18} \mathrm{~kg} \mathrm{~N}\right)$. For large-scale questions, fluorometry is an appropriate technique. For questions that require finer resolution, such as biologic incorpo- 
ration of rock-bound N (Morford et al., 2011), more method development is required.

The fluorometry technique has the potential to increase the number of analyses of under-sampled rock types such as volcanics and middle- to lower-crustal xenoliths. These poorly sampled reservoirs have the potential to sequester large amounts of $\mathrm{N}$, and the continental crust can be both a long-term storage reservoir of $\mathrm{N}$ and an important source of biologically available N (Morford et al., 2011). Thus, determining its abundance is of interest to both geology and biology.

\section{Conclusions}

We have measured $\mathrm{N}$ concentration in a number of rock standards using three different methods - EA mass spectrometry, colorimetry, and newly adapted fluorometry - and compared them to previously published values using neutron activation analysis. Our analysis shows that fluorometry reproduces previously published values for BCR-2 and may also do so for BHVO-2 and G-2 given an additional distillation step. Fluorometry appears more suited to measuring geo$\operatorname{logic} \mathrm{NH}_{4}^{+}$in silicate rocks than either colorimetry or EA mass spectrometry, while mass spectrometry is more suited to high-N samples with significant organic N. No one method appears to be a "gold standard" for geologic $\mathrm{N}$ analysis, and we call for further development in this area. There are several suggested avenues for improving fluorometry, namely improving HF-digestion efficiency and fine-tuning of HF neutralization. Minimizing the volume of liquid required for digestion (HF) or neutralization would increase the sensitivity of the method, which could work for very low concentrations, down to parts per billion levels.

To demonstrate a potential application of fluorometry, we calculated a continental $\mathrm{N}$ budget. This budget is based on analysis of glacial tills (proxy for upper crust), a number of Phanerozoic volcanics, and a variety of mid-crustal xenoliths to augment existing literature analyses. Our approach estimates that between $1.1 \pm 0.4 \times 10^{18} \mathrm{~kg} \mathrm{~N}$ (till + xenolith approach) and $1.48 \pm 0.1 \times 10^{18} \mathrm{~kg} \mathrm{~N}$ (rock abundance approach) is in the continental crust, consistent with recent estimates (Goldblatt et al., 2009; Johnson and Goldblatt, 2015). The fluorometry technique appears most appropriate for these large-scale questions, where exact precision is not required. An additional application could be as an initial analysis to determine approximate concentration, which is a key step in further isotopic investigations.

All methods assessed herein have strengths and weaknesses, which are amplified due to the ability of $\mathrm{N}$ to exist as multiple species in the same sample. We call here again for the development of internationally accepted geologic $\mathrm{N}$ standards. New method development is difficult without such standards, and care should be taken to classify what species of $\mathrm{N}\left(\mathrm{NO}_{3}, \mathrm{NH}_{4}^{+}\right.$, organic $\left.\mathrm{N}, \mathrm{N}_{2}\right)$ is being measured. We also report the first $\delta^{15} \mathrm{~N}$ values for a series of rock standards, as isotope values should be part of any international standard development.

Data availability. All data accompanying this manuscript are available in the Supplement, which is linked below.

\section{The Supplement related to this article is available online at doi:10.5194/se-8-307-2017-supplement.}

Author contributions. Benjamin W. Johnson, Rana El-Sabaawi, and Colin Goldblatt designed the experiments and overall structure of the research. Samples were collected/procured by Benjamin W. Johnson and Natashia Drage. Analysis was done by Benjamin W. Johnson, Natashia Drage, and Nova Hanson. Laboratory support and technical input were given by Jody Spence. All authors contributed to the study.

Competing interests. The authors declare that they have no conflict of interest.

Acknowledgements. The authors thank P. Barry and one anonymous reviewer for their constructive feedback and the editors at Solid Earth (A. Di Muro and J. Gottsmann). The authors acknowledge an NSERC Discovery grant to Colin Goldblatt for funding Colin Goldblatt and Benjamin W. Johnson, a University of Victoria NSERC Undergraduate Student Research Award to Natashia Drage, and NSERC awards to Rana El-Sabaawi for funding support. Nitrogen isotope measurements were done at the University of Washington and were funded by the Virtual Planetary Laboratory.

Edited by: A. Di Muro

Reviewed by: P. Barry and one anonymous referee

\section{References}

Ader, M., Thomazo, C., Sansjofre, P., Busigny, V., Papineau, D., Laffont, R., Cartigny, P., and Halverson, G. P.: Interpretation of the nitrogen isotopic composition of Precambrian sedimentary rocks: Assumptions and perspectives, Chem. Geol., 429, 93-110, 2016.

Barry, P. and Hilton, D.: Release of subducted sedimentary nitrogen throughout Earth's mantle, Geochemical Perspectives Letters, 2, 148-159, 2016.

Barry, P., Hilton, D., Halldórsson, S., Hahm, D., and Marti, K.: High precision nitrogen isotope measurements in oceanic basalts using a static triple collection noble gas mass spectrometer, Geochem. Geophys. Geosys., 13, 1-16, doi:10.1029/2011GC003878, 2012.

Bebout, G. and Fogel, M.: Nitrogen-isotope compositions of metasedimentary rocks in the Catalina Schist, California: implications for metamorphic devolatilization history, 
Geochim. Cosmochim. Ac., 56, 2839-2849, doi:10.1016/00167037(92)90363-N, 1992.

Boyd, S. R.: Determination of the ammonium content of potassic rocks and minerals by capacitance manometry: a prelude to the calibration of FTIR microscopes, Chem. Geol., 137, 57-66, doi:10.1016/S0009-2541(96)00150-7, 1997.

Bräuer, K. and Hahne, J.: Methodical aspects of the ${ }^{15} \mathrm{~N}$-analysis of Precambrian and Paleozoic sediments rich in organic matter, Chem. Geol., 218, 361-368, doi:10.1016/j.chemgeo.2005.01.004, 2005.

Busigny, V., Cartigny, P., and Philippot, P.: Nitrogen isotopes in ophiolitic metagabbros: A re-evaluation of modern nitrogen fluxes in subduction zones and implication for the early Earth atmosphere, Geochim. Cosmochim. Ac., 75, 7502-7521, doi:10.1016/j.gca.2011.09.049, 2011.

Canil, D. and Lacourse, T.: An estimate for the bulk composition of juvenile upper continental crust derived from glacial till in the North American Cordillera, Chem. Geol., 284, 229-239, 2011.

Goldblatt, C., Claire, M., Lenton, T., Matthews, A., Watson, A., and Zahnle, K.: Nitrogen-enhanced greenhouse warming on early Earth, Nat. Geosci., 2, 891-896, doi:10.1038/ngeo692, 2009.

Goldschmidt, V. M.: The principles of distribution of chemical elements in minerals and rocks, The seventh Hugo Müller Lecture, delivered before the Chemical Society on March 17th, 1937, J. Chem. Soc., 655-673, 1937.

Govindaraju, K.: Compilation of working values and sample description for 383 geostandards, Geostandards Newsletter, 18, 1158, 1994.

Haendel, D., Mühle, K., Nitzsche, H.-M., Stiehl, G., and Wand, U.: Isotopic variations of the fixed nitrogen in metamorphic rocks, Geochim. Cosmochim. Ac., 50, 749-758, doi:10.1016/00167037(86)90351-0, 1986.

Hall, A.: Application of the indophenol blue method to the determination of ammonium in silicate rocks and minerals, Appl. Geochem., 8, 101-105, 1993.

Holmes, R. M., Aminot, A., Kérouel, R., Hooker, B. A., and Peterson, B. J.: A simple and precise method for measuring ammonium in marine and freshwater ecosystems, Can. J. Fish. Aquat. Sci., 56, 1801-1808, 1999.

Honma, H. and Itihara, Y.: Distribution of ammonium in minerals of metamorphic and granitic rocks, Geochim. Cosmochim. Ac., 45, 983-988, doi:10.1016/0016-7037(81)90122-8, 1981.

Johnson, B. W. and Goldblatt, C.: The Nitrogen Budget of Earth, Earth Sci. Rev., 148, 150-173, doi:10.1016/j.earscirev.2015.05.006, 2015.
Kolesov, G. M.: Neutron activation analysis of environmental materials, Analyst, 120, 1457-1460, 1995.

Larocque, J. and Canil, D.: The role of amphibole in the evolution of arc magmas and crust: the case from the Jurassic Bonanza arc section, Vancouver Island, Canada, Contrib. Mineral. Petr., 159, 475-492, doi:10.1007/s00410-009-0436-z, 2010.

Marty, B.: Nitrogen content of the mantle inferred from $\mathrm{N}_{2}-$ $\mathrm{Ar}$ correlation in oceanic basalts, Nature, 377, 326-329, doi:10.1038/377326a0, 1995.

Morford, S. L., Houlton, B. Z., and Dahlgren, R. A.: Increased forest ecosystem carbon and nitrogen storage from nitrogen rich bedrock, Nature, 477, 78-81, doi:10.1038/nature10415, 2011.

Murty, S., Shukla, P., and Goel, P.: Nitrogen in stone meteorites and terrestrial standards, Geochem. J., 17, 165-183, 1983.

Norris, T. L. and Schaeffer, O. A.: Total nitrogen content of deep sea basalts, Geochim. Cosmochim. Ac., 46, 371-379, 1982.

Roth, A. S., Bourdon, B., Mojzsis, S. J., Rudge, J. F., Guitreau, M., and Blichert-Toft, J.: Combined ${ }^{147},{ }^{146} \mathrm{Sm}^{-143,142} \mathrm{Nd}$ constraints on the longevity and residence time of early terrestrial crust, Geochem. Geophys. Geosys., 15, 2329-2345, 2014.

Sevigny, J., Parrish, R., Donelick, R., and Ghent, E.: Northern Monashee Mountains, Omineca crystalline belt, British Columbia: Timing of metamorphism, anatexis, and tectonic denudation, Geology, 18, 103-106, 1990.

Shukla, P., Kothari, B., and Goel, P.: Simultaneous determination of nitrogen and lithium by thermal neutron activation analysis, Anal. Chim. Ac., 96, 259-269, 1978.

Stiueken, E. E.: A test of the nitrogen-limitation hypothesis for retarded eukaryote radiation: nitrogen isotopes across a Mesoproterozoic basinal profile, Geochim. Cosmochim. Ac., 120, 121139, 2013.

von der Handt, A. and Dalou, C.: Quantitative EPMA of Nitrogen in Silicate Glasses, Microsc. Microanal., 22, 1810-1811, doi:10.1017/S1431927616009892, 2016.

Wedepohl, H. K.: The composition of the continental crust, Geochim. Cosmochim. Ac., 59, 1217-1232, doi:10.1016/00167037(95)00038-2, 1995.

Wlotzka, F.: Handbook of Geochemistry, II, Springer-Verlag, 1972.

Yokochi, R., Marty, B., Chazot, G., and Burnard, P.: Nitrogen in peridotite xenoliths: Lithophile behavior and magmatic isotope fractionation, Geochim. Cosmochim. Ac., 73, 4843-4861, doi:10.1016/j.gca.2009.05.054, 2009. 